\title{
STUDIES ON THE PRODUCTIVITY OF NAKED OATS (AVENA NUDA, L.) VARIETY "MINA", GROWN UNDER CONDITIONS OF ORGANIC FARMING IN SAKAR REGION, BULGARIA
}

\author{
Violeta Vateva, Krasimir Trendafilov \\ Department of Mechanical engineering, \\ Faculty of Techniques and Technologies of Yambol, \\ Trakia University of Stara Zagora, Bulgaria \\ 38 Graf Ignatiev Str., 8600 Yambol, Bulgaria \\ e-mail: vili13@gmail.com, trendafilov@outlook.com
}

\begin{abstract}
The productivity of cereals is the most important indicator that interested the farmers. Grown in different regions and under different conditions the productivity of agricultural crops varies. In most cases the yields obtained from the same cultures grown under conditions of organic farming are lower.

This study was performed in Sakar agro-ecological region in terms of organic farming. The soil is leached cinnamon forest (Chromic Luvisols), slightly eroded. The aim of the experiment is to determine the productivity of naked oats variety "Mina" grown in terms of organic farming. In the three years of research with a proper farming and without using of pesticides the oats shows very good survival and productivity.

Grown in ecological environment under the conditions of Sakar region grain yields ranged from 1095 to $1475 \mathrm{~kg} / \mathrm{ha}$. Compared to the average yields of oats grown in terms of conventional farming in Bulgaria, the resulting yields of oats in Sakar region are lower by about $26 \%$. The weight of the grains in a panicle is from 1.42 to $1.84 \mathrm{~g}$, and the weight of 1 grain is averaged $0.054 \mathrm{~g}$. The amount of the resulting straw, which is rich in minerals and trace elements is from 1390 to $1600 \mathrm{~kg} / \mathrm{ha}$.
\end{abstract}

Keywords: spring naked oat, organic farming, productivity, yield of grain, Sakar region.

\section{INTRODUCTION}

The cultivation of cereals in ecological environment is a priority for the countries of the European Union [4, 7]. In the conditions of changing climate and changing environment of growing on these crops, the selection and seed production work on creating varieties suitable for the newly created environment $[2,5,8]$.

The oats is cereal crop, relatively unpretentious to the soil conditions $[3,6]$. He is successfully grown on poorer and acid soils. This increases the area of its cultivation. The qualities of the oat grain in direction of dietetic and healthy eating [11] and of the oat straw, which also has a high nutritional value, make the culture demanded in the market and preferred by farmers for cultivation.

The cultivation of winter or spring forms of oats is a matter of preference by the farmers and here the most vital role played growing conditions. As the development and formation of yield of oat depends on these conditions, the study of the new selected varieties of oats for the various agro regions of the country is imperative. Interest for the practice is the spring naked oat variety "Mina". According to the creators of this variety "it is early variety with high resistance to lodging and having a high resistance to diseases" [1]. These qualities suggest that he could successfully be grown in terms of organic farming.

The objective of this study is to explore the productive capabilities of the spring naked oat variety "Mina" grown in Sakar region in conditions of organic farming. Reported are structural

IRTIIE Vol. 5, No. 3, 2017 ISSN 1314-8788 (print), ISSN 1314-8796 (online), doi: 10.15547/artte.2017.03.003 


\section{ARTTIE $Y$}

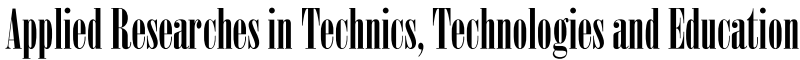

Journal of the Faculty of Technics and Technologies, Trakia University https://sites.google.com/a/trakia-uni.bg/artte/

elements that determined the yield (number of panicles of $1 \mathrm{~m}^{2}$, number of grains in 1 panicle, weight of grains in 1 panicle, weight of 1000 grains) and yield of grain and straw. A comparison was made of the resulting yields of oats grown in organic farming conditions in relation to the average yields of oats in Bulgaria.

\section{MATERIAL AND METHODS}

The experiment was conducted under field conditions in three consecutive years $(2009,2010$ and 2011) in experimental field of ISSAPP "N. Poushkarov", Sofia. The field is representative for Sakar agro-ecological region. The soil is leached cinnamon forest (Chromic Luvisols). The contents of humus, total nitrogen and total phosphorus in the plow layer are respectively $1.55 \% ; 0.073 \%$ and $0.071 \%$ [10]. The specificity of the region is determined primarily by the location and the climatic conditions that shape it as dry and warm, influenced by Mediterranean currents penetrating along the River Tundzha.

The tested naked oats variety "Mina" is Bulgarian selection, a variation of the spring varieties of oats. Factored in three repetitions with size of the experimental area of $20 \mathrm{~m}^{2}(2 \times 10 \mathrm{~m})$, the oats is grown in ecological conditions in an environment of organic farming, i.e. without the use of fertilizers and pesticides.

The technology of cropping follows the chronology for the preparation and sowing of spring crops - deep plowing after harvest of the predecessor, pre-sowing cultivations during the second half of the month of February (once disking and cultivating). The sowing of oats during the three years was carried out in early March with sowing rate $180 \mathrm{~kg} / \mathrm{ha}$. For the determination of the biometric indicators is performed morphological analysis of 10 labeled plants at each repetition. Harvesting is carried out in phase technological maturity. As experienced areas are small and is difficult to use mechanized equipment according to the relief of the field, the seeding and harvesting are carried out by hand.

\section{RESULTS AND DISCUSSION}

The productivity of oats, as with all crops is dependent on the manifestation of climate indicators. Their unfavorably manifestation may negatively affect its vegetative development and consequently affects productivity.

Sakar agro-ecological region enters in the ranking of Bulgaria as one of the warmest and with pronounced periods of drought [10]. The norm of rainfall in the region is lower than the average rate for the country and the average temperature is one of the highest in Bulgaria.

And in the three years of research in the manifestation of climate indicators are observed deviations from the established norms. The deviation is in annual values as well as in the values during the vegetation period (fig. 1).

The quantities of rainfall are essential for soil preparation, sowing and vegetative development of any culture. In this case, because of the high moisture, soil preparation and in the three years of monitoring is hampered and delayed in time. For this reason, the sowing was late with $7-10$ days. After germination, the vegetative development of the spring oats variety "Mina" during the years of research passed under the conditions of limited quantities of rainfall. The norm of rainfall for the growing season is $270 \mathrm{~mm}$. During the first and the third years the region is poorly secured with moisture $(234.6$ and $211.1 \mathrm{~mm}$ ), and in the second year is hyper-secured with moisture $(348.2 \mathrm{~mm})$. Worryingly high are quantities of rainfall in February and March in the first and the second years, where they exceed the norm $1.5-2.5$ times. During the other months of the growing season the rainfall are even lower. 


\section{ARTITE}

Ipplied Researreches in Technics, Technologies innd Bduration

Journal of the Faculty of Technics and Technologies, Trakia University https://sites.google.com/a/trakia-uni.bg/artte/
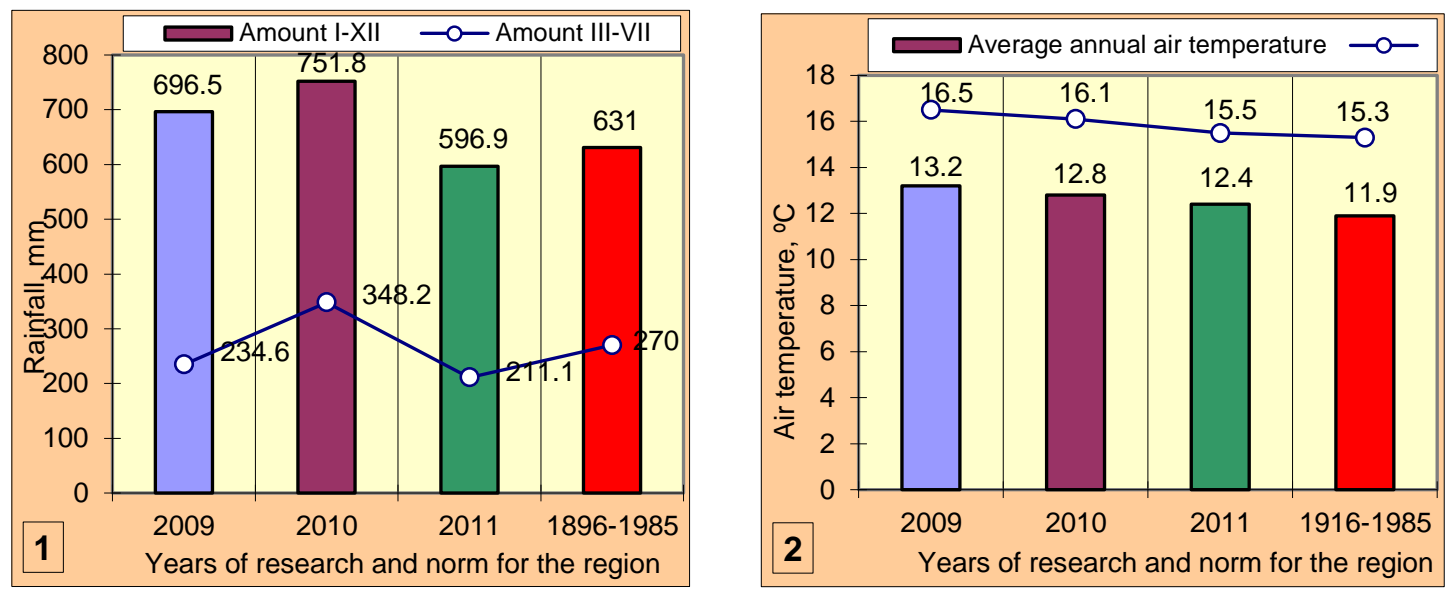

Figure 1. Annual rainfall and rainfall for the growing season (1), average annual air temperature and average air temperature for growing season (2) in the years of research and norm for the region

The values of average annual temperature and the average temperature for the growing season, as evidenced in Figure 1 (2), are higher than the norm for the region and during the three years of research. The increase is in range of $0.3-1.3^{\circ} \mathrm{C}$ for the average annual values and $0.2-1.2{ }^{\circ} \mathrm{C}$ for the average values for the growing season. It was found that most tangibly the average temperature has risen during the months of July, August, December and February. During other months it is close or with a small difference from the norm for the region.

The productivity of each cereal is determined by the structural elements constituting its ear. The inflorescence of oats is a panicle and naked variety "Mina" develops one-sided panicle, whose branches are located on one side (fig. 2).

The height of the plants in the phase of technological maturity is an indicator reflecting the overall development of culture during the vegetation period. On figure 3 can be seen that the oats reached the maximum height in the second year of research $-75 \mathrm{~cm}$. Over the next two years the height is respectively 71.1 and $66.5 \mathrm{~cm}$. The correlation between height of the plants and the security with moisture through years of research is evident.
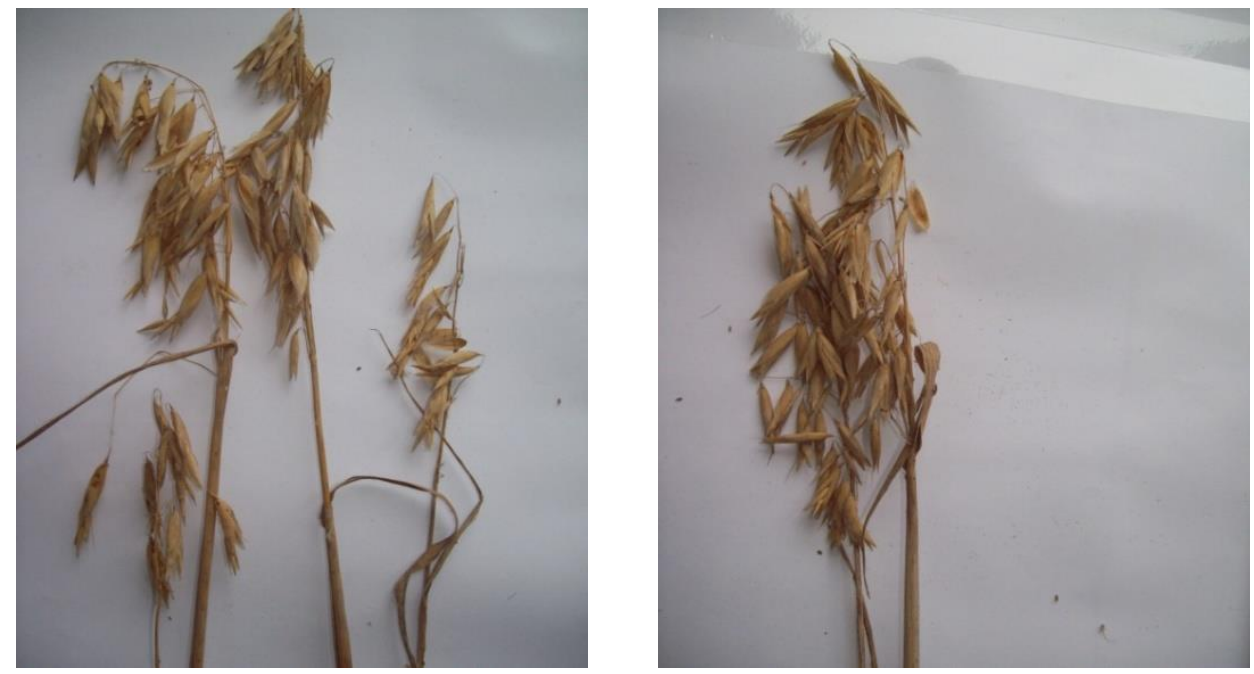

Figure 2. Naked oat "Mina" in phase technological maturity

IRTIIE Vol. 5, No. 3, 2017 ISSN 1314-8788 (print), ISSN 1314-8796 (online), doi: 10.15547/artte.2017.03.003 


\section{IRITIE}

Ipplied Reseirl'ches in Technics, Technologies and Bduration

Journal of the Faculty of Technics and Technologies, Trakia University https://sites.google.com/a/trakia-uni.bg/artte/
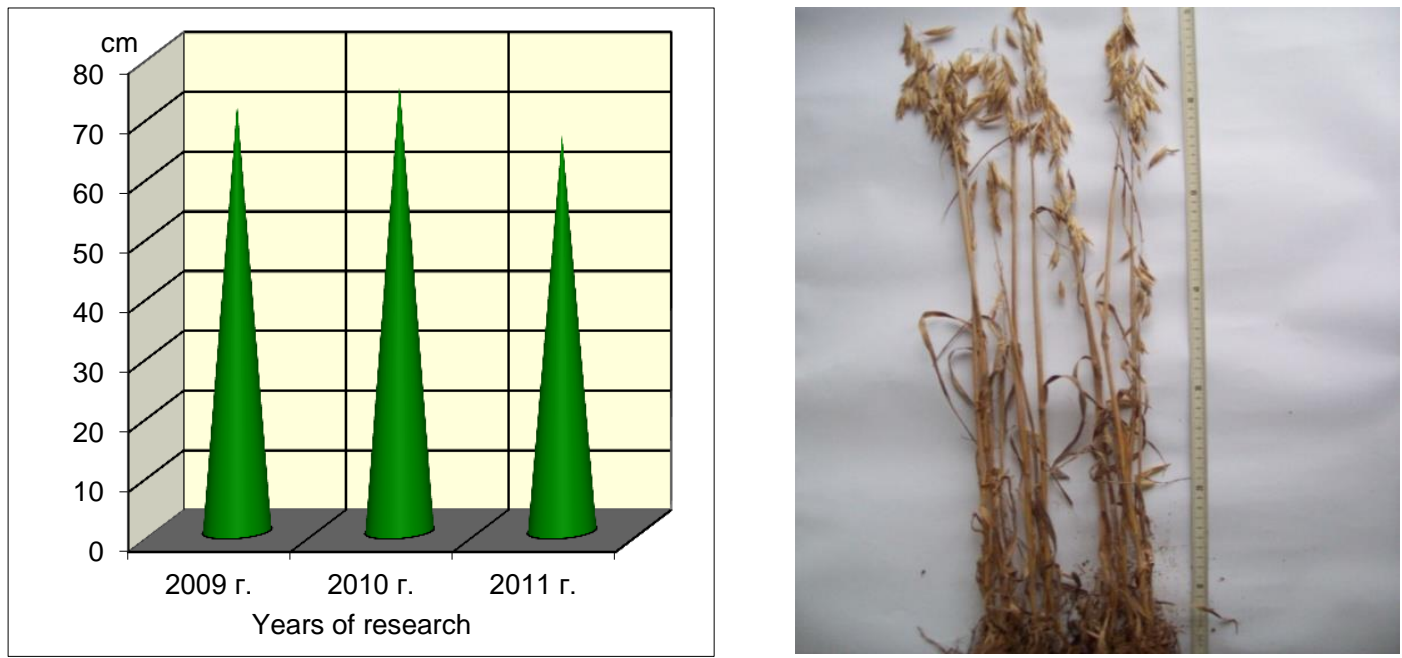

Figure 3. Height of oats in the phase of technological maturity in the years of research

The length of the panicle, the number of grains in it and the weight of the grains are important morphological features which define the productivity of cereals. The number of panicles per $1 \mathrm{~m}^{2}$ varies in the range of 352 to 427 (Table 1). The difference compared to the average for the period is -37 in the first year and +38 in the second year, in the third year the number of panicles is identical to the average for the period. The length of panicle generally does not significantly affect the yield but it is a varietal indicator. Its values in terms of Sakar agro-ecological region is in the range of $19.5-22.7 \mathrm{~cm}$. The weight of the grains in one panicle and the weight of 1 grain are important as value for the formation of yield. The grain of oats is relatively light and this is one of the reasons that the yields of oats are lower than other cereals. For the naked oats variety Mina during the study, the weight of a grain is between 0.051 and $0.056 \mathrm{~g}$, and the weight of the grains in one panicle varies from 1.42 to $1.84 \mathrm{~g}$.

Table 1. Structural elements determining the yield of naked oat variety "Mina" in the years of research and average for the period

\begin{tabular}{|c|c|c|c|c|c|}
\hline Year & $\begin{array}{c}\text { Length of } \\
\text { panicle, } \\
\mathrm{cm}\end{array}$ & $\begin{array}{c}\text { Number of } \\
\text { panicles in 1 } \mathrm{m}^{2}\end{array}$ & $\begin{array}{c}\text { Number of } \\
\text { grains in 1 } \\
\text { panicle }\end{array}$ & $\begin{array}{c}\text { Weight of the } \\
\text { grains in 1 } \\
\text { panicle, g }\end{array}$ & $\begin{array}{c}\text { Average } \\
\text { weight of 1 } \\
\text { grain, } \mathrm{g}\end{array}$ \\
\hline 2009 & 20,8 & 352 & 28 & 1,42 & 0,051 \\
\hline 2010 & 22,7 & 427 & 33 & 1,84 & 0,056 \\
\hline 2011 & 19,5 & 388 & 30 & 1,61 & 0,054 \\
\hline $\begin{array}{c}\text { Average } \\
2009-2011\end{array}$ & 21 & 389 & 30 & 1,62 & 0,054 \\
\hline
\end{tabular}

The grain, straw and chaff of oats are valuable because of its high nutritional value. Under favorable conditions for its development and available nutrients in conventional agriculture, the yields by spring oats in Bulgaria reaches $2000-3000 \mathrm{~kg} / \mathrm{ha}$ [9]. The yields of naked oats variety Mina grown in conditions of organic farming are shown in Figure 4. The yields vary between 1095 and $1475 \mathrm{~kg} / \mathrm{ha}$. According to the results presented in Table 1, the yield of $1475 \mathrm{~kg} / \mathrm{ha}$ was obtained in the second year of research. In this year the security with moisture during the year and for the growing season was the highest. This explains good

IRTIIE Vol. 5, No. 3, 2017 ISSN 1314-8788 (print), ISSN 1314-8796 (online), doi: 10.15547/artte.2017.03.003 


\section{IRTITE}

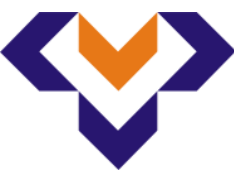

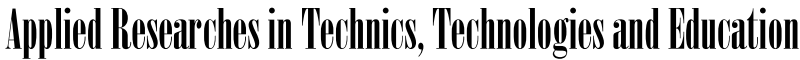

Journal of the Faculty of Technics and Technologies, Trakia University https:///ites.google.com/a/trakia-uni.bg/artte/

vegetative development of oats, better values of the structural elements and the highest real yields obtained from the grain. Compared to the average data for obtained yields from oats in Bulgaria in the same years, yields of grain from naked oat variety "Mina" are lower with 249 $667 \mathrm{~kg} / \mathrm{ha}$. With the smallest difference is the yield of grain in the second year $(1475 \mathrm{~kg} / \mathrm{ha}$ at $1724 \mathrm{~kg} / \mathrm{ha}$ on average for the country).

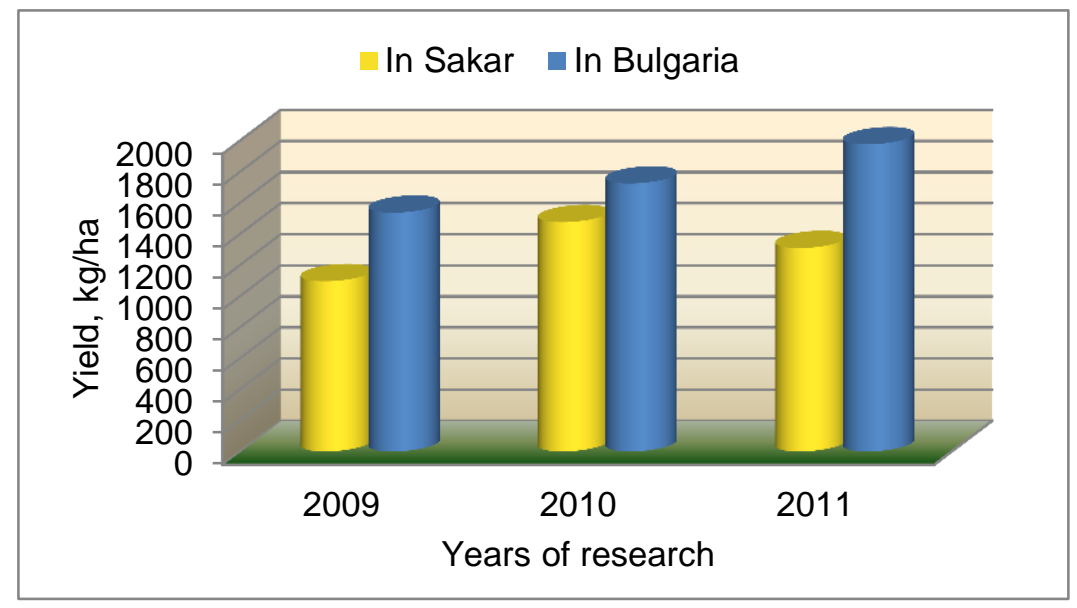

Figure 4. Yields of grain in Sakar region and in the country in the years of research

The quantity of straw from oats, which is a valuable raw material and is looking for animal feed is the range $-1390-1600 \mathrm{~kg} / \mathrm{ha}$. The total yields of grain and straw in the years of the research are between 2485 and $3075 \mathrm{~kg} / \mathrm{ha}$. Average ratio between straw and grain is $54.6: 45.6 \%$. In the years of research this ratio varies between $52: 48 \%$ and $56: 44 \%$ (fig. 5). On this figure can be seen that the quantity of straw is more than the quantity of grain, the grain is in the range of $44-48 \%$ of the total weight of straw and grain, and the quantity of straw is between $52-56 \%$. The smallest is the difference in the ratio of straw/grain in the second year (52:48\%) when actually are received the highest yields of grain.
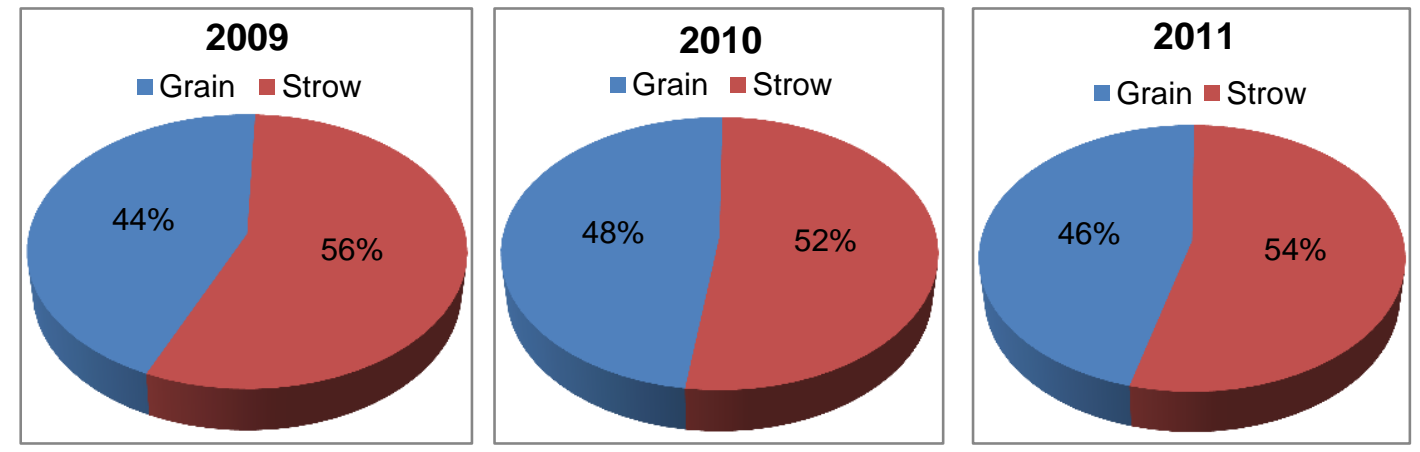

Figure 5. Ratio between the yields of grain and straw during the years of research

\section{CONCLUSIONS}

From the analysis of the results for the productivity of naked oat variety "Mina", grown under conditions of organic farming in Sakar region can make the following conclusions:

1. Climatic parameters rainfall and temperature in Sakar region during the period of research vary considerably, and this affects the productivity of naked oats variety "Mina".

IRTIIE Vol. 5, No. 3, 2017 ISSN 1314-8788 (print), ISSN 1314-8796 (online), doi: 10.15547/artte.2017.03.003 


\section{ARTTIE $Y$}

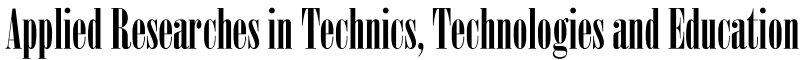

Journal of the Faculty of Technics and Technologies, Trakia University https://sites.google.com/a/trakia-uni.bg/artte/

2. The height of the plants in the phase of technological maturity is average $71 \mathrm{~cm}$. In drought conditions the plants remain $66.5 \mathrm{~cm}$ in height, and in conditions of good security with moisture reach $75 \mathrm{~cm}$.

3. The number of panicles per $1 \mathrm{~m}^{2}$ is average 389 , and the average number of grains per panicle is 30. In better conditions for growing, the number of grains per $1 \mathrm{~m}^{2}$ is 427 , the number of grains per panicle is 33 and the weight of a grain is average $0,054 \mathrm{~g}$.

4. The productivity of spring naked oat variety "Mina" in conditions of organic farming in Sakar region primarily depend on the climatic conditions of the region. The yield of grain average for the period of research was $1293 \mathrm{~kg} / \mathrm{ha}$. This yield is lower with $452 \mathrm{~kg} / \mathrm{ha}$ versus the average yields of oats for the country obtained in the same period.

5. Under favorable agro-meteorological conditions in Sakar region from oats are obtained $1475 \mathrm{~kg} / \mathrm{ha}$ grain and $1600 \mathrm{~kg} / \mathrm{ha}$ straw in conditions of organic farming.

6. The results for the productivity of spring naked oats variety "Mina" indicate that in specific agro-climatic conditions, this variety has good productive potential and could be grown successfully within the region.

\section{REFERENCES}

[1] Antonova N., Stancheva J., Dobrev D., Karadjova J. (1995). Spring naked oats variety Mina. Jubilee scientific conference "90 years IASS Obraztsov chiflik, Ruse" Scientific works, Vol. I, pp. 51-55. (Bg).

[2] Bojanova V., Detchev D. (2009). Problems and prospects associated with the cultivation of cereal species organically. International Science conference, June 4-5, 2009, Stara Zagora, Bulgaria. "Economics and Society development on the Base of Knowledge" Volume I, 322. Agricultural science. Plant studies. (Bg).

[3] Durgan B. R. (1994). Competition - Wild and Cultivated Oats (Crop - Weed Interactions). Oat newsletter, Vol. 42, 58.

[4] IFOAM, (2002). The IFOAM Norms and Organic Guarantee System, by International Federation of Organic Agriculture Movements.

[5] Kuzmova K. (2009). The impact of climate variability on agricultural production of the Republic of Bulgaria. International scientific-practical conference, dedicated to the 75anniversary of education IrGSHA. Coll. Articles "The climate, ecology, farming Eurasia", pp. 38-46. (Ru).

[6] Reeves D. L., Lammers L. (1986). A Revised Look at Herbicides on Oats. Oat newsletter, Vol. 37, pp. 50 - 52.

[7] Scialbba N., Hattam C. (2002). Organic Agriculture, Environment and Food Security, Environment and Natural Resources Series, 4. Rome, Italy: Food and Agriculture Organization (FAO) of the United Nations.

[8] Stoynev K. (2004). Environmental and technological aspects of modern agriculture, Sofia. (Bg).

[9] Terziev G., Yancheva H., et al. (2006). Plant-growing. Electronic edition. (Bg).

[10] Vateva V., Rousseva S. (2007). Influence of mineral fertilization of perennial grasses mixture on its efficiency for reducing surface runoff. Scientific papers. International Conference "Soil - the basis for sustainable agriculture and environmental protection" PablishSaySet Eco-Sofia, pp. 543-546. (Bg).

[11] Zorovski P. (2012). Study on the biological and economic qualities of oats varieties in relation to using them as healthy food for people. (Doctoral thesis). (Bg). 